UDC 347.788 .36

LBC 67.404.3

\title{
RIGHT OF POLICE OFFICER IN REMUNERATION AS SPECIAL TYPE OF THE INTELLECTUAL RIGHTS
}

\author{
Alexander A. Molchanov \\ St.-Petersburg University of the Ministry of the Interior of Russia, St.-Petersburg, Russian Federation \\ Elena S. Afanasyeva \\ St.-Petersburg University of the Ministry of the Interior of Russia, St.-Petersburg, Russian Federation
}

Introduction: in article the possibility provided by the legislator at the worker (author) of the right for remuneration for the work of science, literature or art created by it within labor duties is analysed. In the context of changes of the Civil Code of the Russian Federation the police officer, being the author of office work, also has the right to remuneration for the creative result created by it. Purpose: to analyze whether the legislator provided for the possibility of the employee (the author) the right to remuneration for created within the employment duties the work of science, literature or art. Methods: a methodological basis for this study is a set of scientific methods, among which of particular importance are the systemic method, analysis method and comparative legal method. Results: from the following it follows that the execution by police of their duties, including the implementation of intellectual activity, subject to the provisions of the labor law and in the scope of civil law are not included, the relationship of the transfer of property rights from the police to the employer are civil and are governed by civil law. Since h. 2 tbsp. 15 the Labour Code does not allow for the conclusion of civil-legal contracts which virtually govern the employment relationship of the employee and the employer, therefore, the employment contract may not cover him the signs of a civil contract, with supplement its terms of belonging of the rights to service the product does not remove these conditions which are originally inherent in them civil in nature.

Keywords: remuneration, office work, copyright, intellectual property, creativity, scientific activity.

УДК 347.788 .36

ББК 67.404 .3

\section{ПРАВО СОТРУДНИКА ПОЛИЦИИ НА ВОЗНАГРАЖДЕНИЕ КАК ОСОБЫЙ ВИД ИНТЕЛЛЕКТУАЛЬНЫХ ПРАВ}

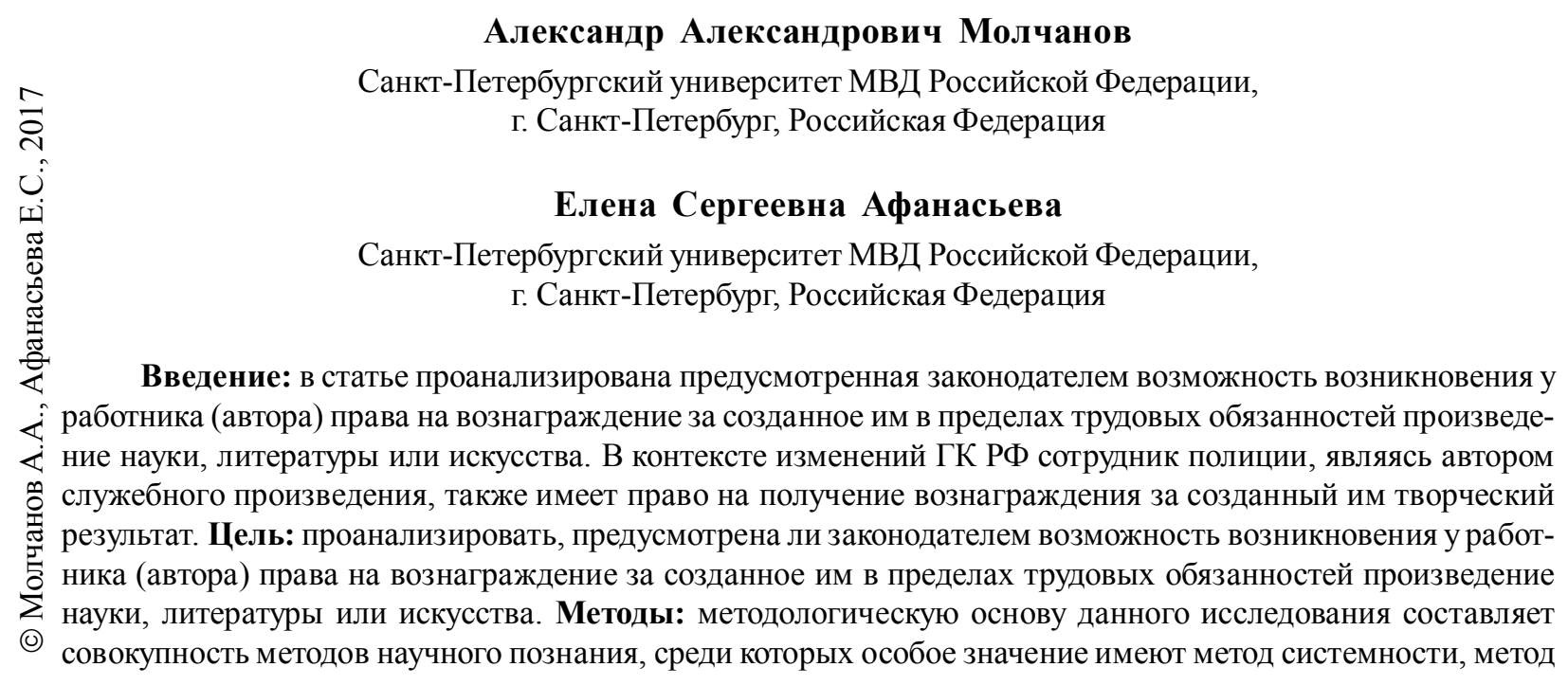


анализа и сравнительно-правовой метод. Результаты: из нижеизложенного следует, что вопросы исполнения сотрудником полиции своих обязанностей, в том числе реализация им интеллектуальной деятельности, обусловливаются нормами трудового права и в область применения гражданского законодательства не входят, отношения же перехода имущественных прав от сотрудника полиции к работодателю являются гражданско-правовыми и регулируются гражданским законодательством. Поскольку ч. 2 ст. 15 ТК РФ не допускает заключения гражданско-правовых договоров, которые практически регулируют трудовые отношения работника и работодателя, следовательно, трудовой договор не может охватывать собой признаки гражданскоправового договора, при этом дополнение его условиями о принадлежности прав на служебное произведение не снимает с данных условий изначально присущий им гражданско-правовой характер.

Ключевые слова: вознаграждение, служебное произведение, авторское право, интеллектуальная собственность, творчество, научная деятельность.

\section{Введение}

Продолжением процесса кодификации авторского права в России стало принятие Государственной Думой Федерального закона от 12 марта 2014 г. № 35-Ф3 [12] (далее-Ф3 № 35Ф3), после введения в действие которого с 1 октября 2014 г. в очередной раз изменилось правовое регулирование служебных произведений, но главнейший принцип принадлежности служебного произведения его автору остался.

Правовая природа служебного произведения раскрывается в ст. 1295 ГК РФ, согласно которой авторские права на произведения науки, литературы и искусства, созданные в пределах установленных для работника (автора) трудовых обязанностей (служебное произведение), принадлежат автору [1, с. 3].

Поскольку п. 2 ч. 1 ст. 1295 ГК РФ сформулирована диспозитивно в отношении принадлежности именно работодателю исключительного права на служебное произведение, работодатель и работник в трудовом или гражданско-правовом договоре могут ввести отступления от указанного правила.

В первоначальной редакции указанной статьи говорилось о трудовом или ином договоре между ними. Предполагалось, что произведения, созданные в порядке служебного задания, выходящего за рамки трудовых обязанностей, должны были регулироваться дополнительным соглашением между работодателем и работником.

В настоящее время упоминание о «трудовом или ином» договоре работодателя и работника в Ф3 № 35-Ф3 заменено указанием на «трудовой или гражданско-правовой договоры». Изменение словосочетания «иным договором» словосочетанием «гражданско- правовым договором» основывается на том, что служебные произведения создаются в связи с выполнением обязанностей работника, предусмотренных трудовым договором. Эти отношения согласно ст. 15 ТК РФ признаются трудовыми и в силу ст. 5 ТК РФ регулируются трудовым законодательством и иными, содержащими нормы трудового права, нормативными правовыми актами.

В то же время в силу ст. 2 ГК РФ основания возникновения и порядок осуществления права собственности и других вещных прав, права на результаты интеллектуальной деятельности и приравненные к ним средства индивидуализации (интеллектуальных прав) устанавливает гражданское законодательство.

\section{Основания и порядок установления размера вознаграждения за использование служебного произведения}

Согласно ныне действующему законодательству создание служебного произведения допустимо только в пределах трудовых обязанностей работника. В связи с этим употребление законодателем в п. 2 ч. 1 ст. 1295 ГК РФ словосочетания «или гражданско-правовым договором» представляется вполне прогрессивным и способствующим развитию служебных произведений в нынешних реалиях.

Заменив в п. 2 ч. 2 ст. 1295 ГК РФ указание о случаях, когда имущественные права на служебное произведение принадлежат автору, указанием на то, что такое право ему возвращается, законодатель предоставил автору возможность независимо распоряжаться исключительным правом на собственное произведение и зарабатывать доход от его использова- 
ния. Так, если работодатель в течение трех лет не начнет осуществлять свое право на использование служебного произведения, то он это право утрачивает, а исключительное право на служебное произведение, к которому работодатель не проявил интереса в течение трехлетнего срока, возвращается автору ввиду бездействия работодателя.

Как мы уже отмечали, по общему правилу исключительное право на использование служебного произведения принадлежит работодателю. По этой причине работодатели пренебрегают заключением с авторами-работниками соответствующих договоров.

В соответствии с п. 2 ч. 3 ст. 1295 ГК РФ, если работодатель в течение трех лет со дня, когда служебное произведение было предоставлено в его распоряжение, начнет его использование или передаст исключительное право другому лицу, автор имеет право на вознаграждение.

Анализ положений российского законодательства показывает, что работодатели игнорируют заключение с авторами соответствующих договоров, а поскольку право на получение авторского вознаграждения напрямую связано с моментом использования произведения работодателем, то, как следствие, выплата вознаграждения практически находится в зависимости от усмотрения работодателя. Работодатель зачастую прибегает к уловке, применяемой в сегодняшней практике, оговаривая, что «авторское вознаграждение включено в заработную плату работника и дополнительной оплате не подлежит». Данное мнение не располагает никаким правовым обоснованием, а лишь содержит в себе почву для будущих конфликтов, ибо не только не представляет возможности установить размер авторского вознаграждения, но и дает возможность работнику, размер заработной платы которого не находится в зависимости от количества созданных им произведений, привести доказательства невыплаты ему авторского вознаграждения. Полагаем, что природа права на вознаграждение за служебное произведение и природа заработной платы его автора диаметрально противоположны - первое имеет гражданско-правовой характер, второе - трудовой.

Цель законодателя - защита интересов автора, который находится в неравном поло- жении в сопоставлении с работодателем. Однако законодатель находит только процессуальную защиту и предоставляет автору, не обладающему сведениями об использовании работодателем служебного произведения, возможность письменно обратиться к работодателю и запросить их у него. В случае неполучения необходимых сведений работник может в соответствии со ст. 1252 ГК РФ обратиться в суд с иском о признании за ним исключительного права на служебное произведение, аргументируя это невыплатой ему авторского вознаграждения.

Незаключение сторонами надлежащего договора является основанием для конфликта между работником и работодателем. В подобной ситуации работодателю нелегко привести доказательства факта выплаты авторского вознаграждения и подтверждения того, что он в действительности владеет исключительным правом на произведение и не попирает имущественные права автора, это обстоятельство имеет важное значение. Кроме того, работодатель должен будет предоставить доказательства использования произведения за истекший трехлетний период.

В связи с этим в п. 2 ч. 3 ст. 1295 ГК РФ законодатель справедливо устанавливает, что размер вознаграждения за использование служебного произведения, условия и порядок его выплаты работодателем определяются договором между ним и работником.

На гражданско-правовую природу такого договора указано в п. 26 Постановления Пленума ВС РФ от 19 июня 2006 г. № 15 «О вопросах, возникших у судов при рассмотрении гражданских дел, связанных с применением законодательства об авторском праве и смежных правах», где говорится, что «размер и порядок выплаты авторского вознаграждения за каждый вид использования служебного произведения устанавливаются договором автора с работодателем. Такой договор носит гражданско-правовой характер, и на него распространяются общие правила о порядке заключения договоров» [6].

В пункте 2 ч. 4 ст. 1295 ГК РФ установлено ограничение оборотоспособности права на вознаграждение за служебное произведение. При этом уточняется, что то вознаграждение, которое было присуждено автору при 
жизни, но не выплачено, переходит по наследству. Иначе говоря, наследники автора имеют право на получение вознаграждения как части не полученных автором доходов только в случае, когда оно возникло при жизни автора, но автор умер, не успев его осуществить.

В пункте 3 ст. 1295 ГК РФ устанавливается обязанность работодателя по выплате автору вознаграждения за использование служебного произведения, исключительное право на которое в силу договора принадлежит автору, на условиях простой (неисключительной) лицензии.

В гражданско-правовом договоре работодатель и автор определяют пределы использования данного произведения, а также регулируют вопросы размера, условий и порядка выплаты вознаграждения, при возникновении спора их установит суд. Указанное вознаграждение должно быть выплачено автору на основе гражданско-правового договора сверх и независимо от заработной платы, при этом размер вознаграждения не может быть ниже минимальной ставки авторского вознаграждения, установленной Постановлением Правительства РФ от 21 марта 1994 г. № 218 «О минимальных ставках авторского вознаграждения за некоторые виды использования произведений литературы и искусства» [7].

Нормы п. 4 ст. 1295 ГК РФ сформулированы диспозитивно в части права работодателя по обнародованию служебного произведения и указания при его использовании своего имени или наименования, поскольку в договоре между работодателем и автором могут быть отступления от данного правила.

В некоторых случаях произведения создаются в результате совместных созидательных действий нескольких лиц, в результате чего авторские права на данное произведение возникают сразу у нескольких соавторов. Неизбежная предпосылка для соавторства - присутствие совместного творческого труда, вне зависимости от того, создает ли подобное произведение единое целое либо слагается из частей, имеющих собственное независимое значение (п. 1 ст. 1258 ГК РФ).

В основе положений ст. 1258 ГК РФ лежит общая норма п. 4 ст. 1228 ГК РФ, в силу которой права на результат интеллектуальной деятельности, созданный совместным твор- ческим трудом двух и более граждан, принадлежат соавторам совместно [5].

Для возникновения авторских прав на одно произведение у нескольких лиц необходимы непосредственное творческое участие в его создании, а также воплощенный в объективной форме творческий результат совместной деятельности [8, с. 273].

Соавторство неизменно определяется по произведенному результату, а не по ходу работы: принимавшее участие в работе лицо не превращается в соавтора в случае ненахождения выражения творческого результата его труда в произведении. Так, не будут признаваться соавторами и лица, напрямую не принимавшие содействия в творческом процессе по созданию произведения, даже если они оказывали автору техническое, организационное, материальное или иное содействие, не являющееся творческой деятельностью (п. 1 ст. 1228 ГК РФ).

\section{Особенности правового регулирования прав сотрудника полиции на служебные произведения}

С принятием Федерального закона от 8 мая 2010 г. № 83-Ф3 [11] законодатель предусмотрел следующие типы государственных (муниципальных) учреждений: автономные, бюджетные и казенные, специфика которых проявляется в порядке финансирования, в отношениях собственности, своеобразии юридической ответственности, возможности быть правообладателем произведения науки, литературы или искусства и др.

Следует отметить, что с 1 сентября 2014 г. согласно Федеральному закону от 5 мая 2014 г. № 99-Ф3 [10] юридические лица создаются исключительно в тех организационно-правовых формах, которые предусмотрены ГК РФ.

В соответствии со своим гражданскоправовым статусом казенное учреждение МВД России, отнесенное к унитарным некоммерческим организациям, как юридическое лицо участвует в гражданском обороте от своего имени только для совершения сделок, обеспечивающих его внутрихозяйственную деятельность. В остальных случаях следует исходить из того, что сделки соответствующего ведомства должны рассматриваться как 
действия самого казенного учреждения МВД России [3, с. 65].

Действующее гражданское законодательство регулирует деятельность казенных учреждений МВД как обычных субъектов гражданских правоотношений. Одним из направлений деятельности, приносящей доход, выступает деятельность, связанная с созданием интеллектуальной собственности. Доходы, полученные от указанной деятельности, поступают в соответствующий бюджет бюджетной системы Российской Федерации (п. 4 ст. 298 ГК РФ, п. 3, 5 ст. 41, п. 1 ст. 51 БК РФ).

Служебные произведения создают и сотрудники полиции, в обязанности которых может входить выполнение творческих работ. Этот вывод мы основываем на том, что в п. 1 ст. 11 Федерального закона от 7 февраля 2011 г. № 3-Ф3 «О полиции» закреплена обязанность сотрудников полиции использовать в своей деятельности достижения науки и техники, информационные системы, сети связи, а также современную информационно-телекоммуникационную инфраструктуру [13]. В системе МВД России существует масса учреждений, непосредственной задачей которых не является осуществление основных задач органов внутренних дел, они выполняют вспомогательные, но не менее важные функции, которые в конечном счете обеспечивают полноценное функционирование всей системы в целом [4].

Сотрудники полиции имеют право сами достигать определенных научных и иных творческих результатов, осуществляя по совместительству с основной работой научную и иную творческую деятельность [4, с. 141]. Данное право сотрудников полиции закреплено в п. 4 ст. 34 Федерального закона от 30 ноября 2011 г. № 342-Ф3 «О службе в органах внутренних дел Российской Федерации» [14].

Как мы уже отмечали, вопрос о регулировании отношений автора и работодателя в применении ст. 1295 ГК РФ решается таким образом, что сотруднику полиции, посредством творческого труда которого создается служебное произведение, принадлежат авторские права на созданное им служебное произведение. Данные права включают в себя помимо исключительного права на использование произведения и личные неимущественные (иные) авторские права. Сотрудник полиции - автор служебного произведения - затрачивает необходимые усилия, применяет накопленный им опыт и знания для того, чтобы создать в пределах своей трудовой функции произведение науки, литературы или искусства, но, несмотря на это, именно работодатель - Федеральное казенное учреждение МВД РФ в соответствии с п. 2 ст. 1295 ГК РФ обладает исключительным правом на данное служебное произведение.

В рамках осуществляемой сотрудниками полиции научной или иной творческой деятельности создается достаточно большое количество служебных произведений. Под научной (научно-исследовательской) деятельностью согласно п. 6 Приказа МВД России от 18 марта 2013 г. № 150 следует понимать деятельность, направленную на приобретение и применение новых знаний, научных результатов в сфере внутренних дел [9].

Основывающийся на Федеральном законе «О полиции» Приказ МВД России от 20 июля 2015 г. № 780 «О подготовке учебных и научных изданий в системе МВД России» содержит конкретные положения, реализуемые в целях повышения качества литературы, используемой в образовательном процессе, научной деятельности образовательных учреждений и научно-исследовательских организаций системы МВД России, в том числе определяет порядок подготовки служебных произведений к изданию в соответствии со сводным тематическим планом централизованного выпуска учебных и научных изданий и с планами издательской деятельности образовательных и научных организаций системы МВД России на год.

\section{Выводы}

Несмотря на то что законодатель в ст. 1295 ГК РФ отказался от упоминания о служебных обязанностях или служебном задании, в рамках которых создавалось служебное произведение, тем не менее в соответствии с положениями названных ранее приказов МВД подготовка и использование служебных произведений в системе МВД России осуществляются в плановом порядке.

Из вышеизложенного следует, что вопросы исполнения сотрудником полиции своих обя- 
занностей, в том числе реализация им интеллектуальной деятельности, обусловливаются нормами трудового права и в область применения гражданского законодательства не входят, отношения же перехода имущественных прав от сотрудника полиции к работодателю являются гражданско-правовыми и регулируются гражданским законодательством. Поскольку ч. 2 ст. 15 ТК РФ не допускает заключения гражданско-правовых договоров, которые практически регулируют трудовые отношения работника и работодателя, следовательно, трудовой договор не может охватывать собой признаки гражданско-правового договора, при этом дополнение его условиями о принадлежности прав на служебное произведение не снимает с данных условий изначально присущий им гражданско-правовой характер.

Именно поэтому в данном случае используются нормы п. 2 ст. 1295 ГК РФ, определяющие, что предметом договора не могут быть права на использование служебных произведений, которые сотрудник полиции должен будет создать в дальнейшем. Противоречащие законодательству условия договора на основании п. 2 ст. 168 ГК РФ признаются недействительными. В подобных случаях, при возникновении спора о принадлежности исключительных прав на созданное служебное произведение, трудовой договор не может использоваться в качестве допустимого доказательства.

\section{СПИСОК ЛИТЕРАТУРЫ}

1. Афанасьева, Е. С. Защита авторских прав на служебные произведения сотрудников полиции / Е. С. Афанасьева // Роль гражданского законодательства в обеспечении основных направлений деятельности МВД России : материалы вуз. науч.практ. конф., г. Санкт-Петербург, 26 дек. 2014 г. / сост. С. С. Желонкин. - СПб. : Изд-во С.-Петерб. ун-та МВД России, 2015. - С. 3-7.

2. Молчанов, А. А. Изменение общих положений гражданского законодательства о юридических лицах в системе МВД России / А. А. Молчанов, А. В. Шахматов // Вестник Санкт-Петербургского университета МВД России. - 2012. - № 2 (54). - С. 95-98.

3. Молчанов, А. А. Исключительное право казенных учреждений на служебные произведения в системе МВД России / А. А. Молчанов, Е. С. Афанасьева // Вестник Санкт-Петербургского университета МВД России. - 2015. - № 3 (67). - С. 64-67.
4. Молчанов, А. А. Право на доходы, получаемые от разрешенной деятельности казенными учреждениями МВД России, реализующими служебные произведения, созданные их сотрудниками / А. А. Молчанов, Е. С. Афанасьева // Предпринимательство и бизнес в условиях экономической нестабильности : материалы III Междунар. науч. конгр., 24-25 июня 2015 г.М. : Науч. консультант, 2015. - С. 141-143.

5. Молчанов, А. А. Эволюция законодательства, регламентирующего авторское право на создание служебных произведений в МВД России в постсоветский период / А. А. Молчанов, Е. С. Афанасьева // Вестник Волгоградского государственного университета. Серия 5, Юриспруденция. -2015. № 4 (29). - С. 114-122.

6. Постановление Пленума Верховного Суда РФ «О вопросах, возникших у судов при рассмотрении гражданских дел, связанных с применением законодательства об авторском праве и смежных правах» от 19 июня 2006 г. № 15 // Российская газета. - 2006. - 28 июня (№ 137).

7. Постановление Правительства РФ «О минимальных ставках авторского вознаграждения за некоторые виды использования произведений литературы и искусства» от 21 марта 1994 г. № 218 // Собрание актов Президента и Правительства РФ. 1994. - № 13. - Ст. 994.

8. Постатейный научно-практический комментарий к части четвертой Гражданского кодекса Российской Федерации. В 2 кн. Кн. 1 / под ред. Ю. А. Дмитриева, А. А. Молчанова. - М. : Буквоед, 2008. $-800 \mathrm{c}$.

9. Приказ МВД России «Об организации научного обеспечения и применении положительного опыта в органах внутренних дел Российской Федерации и внутренних войсках МВД России» от 18 марта 2013 г. № 150. - Электрон. текстовые дан. Режим доступа: http://base.consultant.ru/cons/cgi/ online.cgi?req $=$ doc; base $=\mathrm{EXP} ; \mathrm{n}=588117$ (дата обращения: 24.10.2015). - Загл. с экрана.

10. Федеральный закон «О внесении изменений в главу 4 части первой Гражданского кодекса Российской Федерации и о признании утратившими силу отдельных положений законодательных актов Российской Федерации» от 5 мая 2014 г. № 99-Ф3 // Собрание законодательства РФ. - 2014. - № 19. Ст. 2304.

11. Федеральный закон «О внесении изменений в отдельные законодательные акты Российской Федерации в связи с совершенствованием правового положения государственных (муниципальных) учреждений» от 8 мая 2010 г. № 83-Ф3 : (ред. от 31 дек. 2014 г.) // Собрание законодательства РФ. 2010. - № 19. - Ст. 2291.

12. Федеральный закон «О внесении изменений в части первую, вторую и четвертую Граждан- 
ского кодекса Российской Федерации и отдельные законодательные акты Российской Федерации» от 12 марта 2014 г. № 35-Ф3 // Собрание законодательства РФ. - 2014. - № 11. - Ст. 1100.

13. Федеральный закон «О полиции» от 7 февр. 2011 г. № 3-Ф3 // Собрание законодательства РФ. 2011. - № 7. - Ст. 900.

14. Федеральный закон «О службе в органах внутренних дел Российской Федерации и внесении изменений в отдельные законодательные акты Российской Федерации» от 30 нояб. 2011 г. № 342-Ф3 // Собрание законодательства РФ. - 2011. - № 49. Ст. 7020.

\section{REFERENCES}

1. Afanasyeva E.S. Zashchita avtorskikh prav na sluzhebnye proizvedeniya sotrudnikov politsii [Copyright Protection for Works of Service of Police Officers]. Rol grazhdanskogo zakonodatelstva $v$ obespechenii osnovnykh napravleniy deyatelnosti MVD Rossii: materialy vuz. nauch.-prakt. konf., St. Peterburg, 26 dek. 2014 g. [The Role of Civil Law in Ensuring the Basic Directions of Activity of the MIA of Russia: Materials of University Scientific-Practical Conference, Saint Petersburg, December 26, 2014]. Saint Petersburg, Izd-vo S.-Peterb. un-ta MVD Rossii, 2015, pp. 3-7.

2. Molchanov A.A., Shakhmatov A.V. Izmenenie obshchikh polozheniy grazhdanskogo zakonodatelstva o yuridicheskikh litsakh v sisteme MVD Rossii [Change of the General Provisions of the Civil Legislation on Legal Entities in the System of the Ministry of Internal Affairs of Russia]. Vestnik Sankt-Peterburgskogo universiteta MVD Rossii, 2012, no. 2(54), pp. 95-98.

3. Molchanov A.A., Afanasyeva E.S. Isklyuchitelnoe pravo kazennykh uchrezhdeniy na sluzhebnye proizvedeniya v sisteme MVD Rossii [The Exclusive Right of State Institutions on Employment Works in the Ministry of Interior of Russia]. Vestnik Sankt-Peterburgskogo universiteta MVD Rossii, 2015, no. 3 (67), pp. 64-67.

4. Molchanov A.A., Afanasyeva E.S. Pravo na dokhody, poluchaemye ot razreshennoy deyatelnosti kazennymi uchrezhdeniyami MVD Rossii, realizuyushchimi sluzhebnye proizvedeniya, sozdannye ikh sotrudnikami [The Right to the Income Derived from the Activities Authorized by State Organisations of the Russian Interior Ministry, Implementing a Service Work Created by Their Employees]. Predprinimatelstvo i biznes v usloviyakh ekonomicheskoy nestabilnosti: materialy III Mezhdunar. nauch. kongr., 24-25 iyunya 2015 g. [Entrepreneurship and Business in the Conditions of Economic Instability: Proceedings of the 3rd International
Scientific Congress, June 24-25, 2015]. Moscow, Nauchnyykonsultant Publ., 2015, pp. 141-143.

5. Molchanov A.A., Afanasyeva E.S. Evolyutsiya zakonodatelstva, reglamentiruyushchego avtorskoe pravo na sozdanie sluzhebnykh proizvedeniy v MVD Rossii v postsovetskiy period [Evolution of the Legislation Regulating the Copyright for the Creation of Official Works in the Russian Interior Ministry in the Post-Soviet Period]. Vestnik Volgogradskogo gosudarstvennogo universiteta. Seriya 5, Yurisprudentsiya [Science Journal of Volgograd State University. Jurisprudence], 2015, no. 4 (29), pp. 114-122.

6. Postanovlenie Plenuma Verkhovnogo suda $\mathrm{RF}$ «O voprosakh, voznikshikh u sudov pri rassmotrenii grazhdanskikh del, svyazannykh s primeneniem zakonodatelstva ob avtorskom prave i smezhnykh pravakh» ot 19.06.2006 № 15 [The Decree of Plenum of the Supreme Court of the Russian Federation "On the Issues Arising in Courts while Considering Civil Cases Relating to the Application of the Legislation on Copyright and Related Rights" of June 19, 2006 no. 15]. Rossiyskaya gazeta, 2006, June 28, no. 137.

7. Postanovlenie Pravitelstva $\mathrm{RF} « \mathrm{O}$ minimalnykh stavkakh avtorskogo voznagrazhdeniya za nekotorye vidy ispolzovaniya proizvedeniy literatury i iskusstva» ot 21.03.1994 № 218 [The Decree of the Government of the Russian Federation of March 21, 1994 no. 218 “On the Minimum Rates of Royalties for Certain Types of Use of Works of Literature and Art"]. Sobranie aktov Prezidenta i Pravitelstva RF, 1994, no. 13, art. 994.

8. Dmitriev Yu.A., Molchanov A.A., eds. Postateynyy nauchno-prakticheskiy kommentariy $k$ chasti chetvertoy Grazhdanskogo kodeksa Rossiyskoy Federatsii. V 2 kn. Kn. 1 [Itemized Scientific and Practical Commentary to Part Four of the Civil Code of the Russian Federation. In 2 Books. Book 1]. Moscow, Bukvoed Publ., 2008. 800 p.

9. Prikaz MVD Rossii «Ob organizatsii nauchnogo obespecheniya $i$ primenenii polozhitelnogo opyta $v$ organakh vnutrennikh del Rossiyskoy Federatsii i vnutrennikh voyskakh MVD Rossii» ot 18.03.2013 № 150 [The Order of the Russian Interior Ministry "On the Organization of Scientific Support and the Use of Positive Experience in the Internal Affairs of the Russian Federation and Internal Troops of the MIA of Russia" of March 18, 2013 no. 150]. Available at: http://base.consultant.ru/ cons/cgi/online.cgi?req=doc; base $=\mathrm{EXP} ; \mathrm{n}=588117$. (accessed October 24, 2015).

10. Federalnyy zakon «O vnesenii izmeneniy v glavu 4 chasti pervoy Grazhdanskogo kodeksa Rossiyskoy Federatsii i o priznanii utrativshimi silu otdelnykh polozheniy zakonodatelnykh aktov Rossiyskoy Federatsii» ot 05.05.2014 № 99-FZ [The 
Federal Law "On Amendments to Chapter 4 of Part One of the Civil Code of the Russian Federation and on Invalidation of Individual Provisions of Legislative Acts of the Russian Federation" of May 5, 2014 no. 99-FL]. Sobranie zakonodatelstva RF, 2014, no. 19, art. 2304

11. Federalnyy zakon «O vnesenii izmeneniy v otdelnye zakonodatelnye akty Rossiyskoy Federatsii v svyazi s sovershenstvovaniem pravovogo polozheniya gosudarstvennykh (munitsipalnykh) uchrezhdeniy» ot 08.05.2010 № 83-FZ [The Federal Law "On Amendments to Certain Legislative Acts of the Russian Federation in Connection with Improvement of Legal Status of State (Municipal) Institutions" of May 8, 2010 no. 83-FL]. Sobranie zakonodatelstva RF, 2010, no. 19, art. 2291.

12. Federalnyy zakon «O vnesenii izmeneniy v chasti pervuyu, vtoruyu i chetvertuyu Grazhdanskogo kodeksa Rossiyskoy Federatsii i otdelnye zakonodatelnye akty Rossiyskoy Federatsii» ot 12.03.2014 № 35-FZ [The Federal Law “On Amending Part One, Two and Four of the Civil Code of the Russian Federation and Certain Legislative Acts of the Russian Federation" of March 12, 2014 no. 35-FL]. Sobranie zakonodatelstva RF, 2014, no. 11, art. 1100.

13. Federalnyy zakon «O politsii» ot 07.02.2011 № 3-FZ [The Federal Law “On Police” of February 7, 2011 no. 3-FL]. Sobranie zakonodatelstva RF, 2011, no. 7 , art. 900 .

14. Federalnyy zakon «O sluzhbe v organakh vnutrennikh del Rossiyskoy Federatsii i vnesenii izmeneniy v otdelnye zakonodatelnye akty Rossiyskoy Federatsii» ot 30.11.2011 № 342-FZ [The Federal Law "On Service in Bodies of Interior of the Russian Federation and Amendments to Certain Legislative Acts of the Russian Federation" of November 30, 2011 no. 342-FL]. Sobranie zakonodatelstva RF, 2011, no. 49 , art. 7020 .

\section{Information About the Authors}

Alexander A. Molchanov, Doctor of Juridical Sciences, Professor, Assistant Professor, the Department of Civil Law and Civil Procedure, St.-Petersburg University of the Ministry of the Interior of Russia, Letchika Pilyutova St., 1, 198206 St.-Petersburg, Russian Federation, Alexmo153@mail.ru.

Elena S. Afanasyeva, Adjunct, the Department of Civil Law and Civil Procedure, St.-Petersburg University of the Ministry of the Interior of Russia, Letchika Pilyutova St., 1, 198206 St.-Petersburg, Russian Federation, alenamarti14@mail.ru.

\section{Информация об авторах}

Александр Александрович Молчанов, доктор юридических наук, профессор, профессор кафедры гражданского права и гражданского процесса, Санкт-Петербургский университет МВД Российской Федерации, ул. Летчика Пилютова, 1, 198206 г. Санкт-Петербург, Российская Федерация, Alexmol53@mail.ru.

Елена Сергеевна Афанасьева, адъюнкт кафедры гражданского права и гражданского процесса, Санкт-Петербургский университет МВД Российской Федерации, ул. Летчика Пилютова, 1, 198206 г. Санкт-Петербург, Российская Федерация, alenamarti14@mail.ru. 